\title{
ASSESSING IMPROVEMENTS OF SOFTWARE METRICS PRACTICES
}

\author{
Helle Damborg Frederiksen ${ }^{1}$ and Lars Mathiassen ${ }^{2}$ \\ ${ }^{l}$ Department of Computer Science, Aalborg University, Denmark; ${ }^{2}$ Center for Digital \\ Commerce, eCommerce Institute, J. Mack Robinson College of Business, Georgia State \\ University, USA
}

\begin{abstract}
There is an extensive literature on design and implementation of software metrics programs, but our knowledge on how to improve and sustain metrics programs that are already implemented is limited. This paper reports from an action research effort to improve metrics practices in a large software organization. We adopt a comprehensive organizational change model to compare and contrast metrics practices before and after the intervention. Our analysis views the metrics program in its organizational context emphasizing management practices, organizational structures, people, technical systems, and underlying metrics rationale. The paper provides insights into tactics for improving software metrics practices, it provides a specific approach to assess such improvements, and it leads to suggestions for how to make software metrics improvements sustainable.
\end{abstract}

Key words: Software metrics, assessment, organizational change

\section{INTRODUCTION}

Software engineering has matured as a discipline through the past decades (Wasserman, 1996) and the idea of measuring the process and its outcome has come to play an important role. One prominent example of this is Albright's invention of function points as a measure of the size of software (Jones, 1996). Much research has been dedicated to designing software metrics for specific purposes, e.g. object oriented programming (Chidamber \& Kemerer, 1994). Another line of research has been concerned with the implementation of metrics programs, e.g. (Berry \& Jeffery, 2000; 
Hall \& Fenton, 1997; Iversen \& Kautz, 2001). However, recent studies suggest that the benefits from metrics programs are not as great as expected (Dekkers, 1999). It is therefore important to increase our understanding of how metrics practices can be improved (Mendonça \& Basili, 2000). The little research that has been conducted on that issue focuses on adopting data mining to increase the benefit of data (Mendonça \& Basili, 2000) and on validating the theoretical robustness of measures (Kitchenham et al., 1995).

The purpose of our research is to study how we can improve and sustain software metrics programs emphasizing the organizational dimensions of the involved change. Our research is exploratory in nature and based on a longitudinal action research effort (Avison et al., 1999; Kock \& Lau, 2001; Mathiassen, 2002; McKay \& Marshall, 2001) in KMD, a large Danish software organization providing IT-services for municipal institutions. The initial activity of the research effort was a diagnosis of the existing metrics program (Frederiksen \& Mathiassen, 2002; Frederiksen \& Rose, 2003). From this diagnosis improvement efforts were subsequently identified and performed. This paper describes and evaluates the impacts of the improvement efforts at KMD based on Applegate's model for analyzing organizational changes (Applegate, 1994) combined with Kirsch's studies of approaches to control software practices (Kirsch, 1996; Kirsch, 1997). This comprehensive approach allows us to systematically compare and contrast metrics practices before and after the intervention.

The argument proceeds as follows. Section 2 reviews the theoretical background and Section 3 presents the research approach in detail. Section 4 provides a description of the old metrics practices, the change process, and the new metrics practices. Section 5 analyses metrics practices in KMD before and after the intervention. Section 6 presents the key findings, relates them to the literature on software metrics programs, and discusses the implications for both practice and research. Section 7 concludes the argument.

\section{SOFTWARE METRICS}

There is a rich literature on software metrics. Section 2.1 gives an overview of what software metrics are and recommendations on how to implement them. Failing to effectively support software management a metrics program will easily degenerate into a bureaucratic procedure, where data are collected, stored, and reported without having practical consequences (Iversen \& Kautz, 2001; Iversen \& Mathiassen, 2003; Niessink \& Vliet, 1999). Hence, we look in Section 2.2 at different ways in which metrics programs can serve as control mechanisms and in Section 2.3 
at the system of organizational mechanisms that are needed to support their effective operation.

\subsection{Using and improving software metrics}

Our current knowledge on how to define and implement metrics is fairly well developed (Fenton \& Neil, 1999). However, implementing a metrics program is difficult, complex, and likely to fail. It has been estimated that as many as $78 \%$ of metrics programs fail (Dekkers, 1999) and recent research has consequently addressed success factors, e.g. (Hall \& Fenton, 1997; Iversen \& Mathiassen, 2003). Niessink and Vliet (1999) stress focusing on the actual use of a metrics program to make sure that it becomes of value to the organization. This is also the focal point in Iversen and Kautz's (2001) advice for software metrics implementation: Use improvement knowledge, use organizational knowledge, establish a project, establish incentive structures, start by determining goals, start simple, publish objectives and data widely, facilitate debate, and use the data. Mendonça and Basili have developed an approach for improving existing metrics, data collection mechanisms, and the use of data within a software organization (Mendonça $\&$ Basili, 2000). They combine a top-down approach using Goal-QuestionMetric (GQM) and a bottom-up approach based on data mining techniques. Kitchenham et al. (1995) emphasize that validation is critical to the success of a software metrics program. They suggest a framework that can help validate measures and assess their appropriateness in a given situation. The focus in these contributions to improve existing programs is on developing additional managerial support based on available measures and on improving the conceptual validity of the adopted measures. However, there are no efforts directed towards assessing the actual use of a program as a basis for increasing its value for the software organization.

\subsection{Metrics as control mechanisms}

Control plays a critical role in managing software processes and projects effectively (Kirsch, 1997) and in particular in ensuring progress in ongoing development efforts. Kirsch suggests viewing control as a relationship between a controller and a controllee rather than between a supervisor and a subordinate. The controller can be a supervisor, a project manager, a customer, or a consultant. Kirsch lists four modes of control. The two formal modes are behavior and outcome control and the two informal modes are clan and individual control: 
- Behavior: Rules and procedures are articulated, e.g. following a methodology in a software development project. Compliance to rules and procedures is rewarded and assumed to lead to the desired outcome.

- Outcome: Outcomes or goals are articulated, e.g. setting a deadline for the project's delivery of software to the customer. Reward or sanction is based on fulfillment of goals.

- Clan: Common values and beliefs are disseminated and shared by the group (or clan). Identifying, sharing and reinforcing acceptable behavior, e.g. documentation styles for source code, lay the foundation for control.

- Self: This mode of control is like clan control but on the individual level. The values can be implicit to the individual.

A controller adopts a portfolio of these modes to exercise control (Kirsch, 1997). The portfolio depends on task characteristics, role expectations, and project-related knowledge and skills. The purpose of control is to regulate behavior: "...monitoring serves as an information system and makes behaviors observable, whereas evaluation and reward constitute the way in which actions are regulated" (Kirsch, 1996). Indicators from a well functioning metrics program play an important role in this.

\subsection{Metrics programs as organizational systems}

The literature focuses on the internals of metrics programs and less on external factors (Niessink \& Vliet, 1999). To remedy this adopt the wellestablished framework by Applegate (1994) that offers a comprehensive understanding of the key mechanisms required to sustain an organizational effort, see Figure 1.

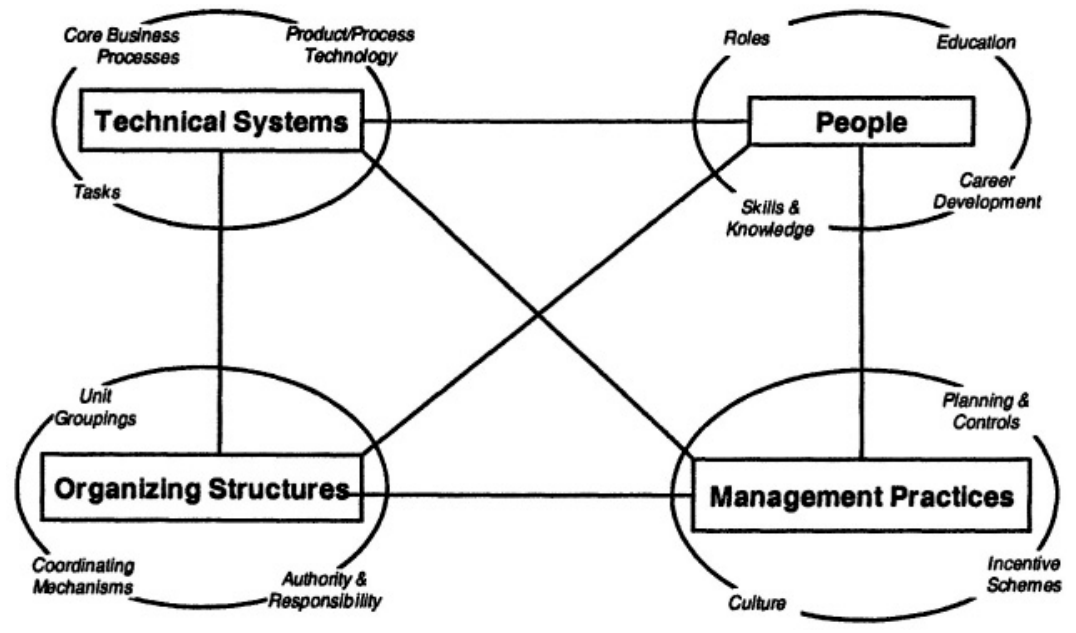

Figure 1. Applegate's model 
The technical systems comprise of (a) core business processes, (b) product/process technology, and (c) tasks. Examples of core business processes could be supplying indicators for managers and benchmarking projects. Examples of product/process technologies could be tools for collecting data and for presenting indicators. Examples of tasks could be prompting project managers for data and analyzing data.

The people dimension addresses (a) roles, (b) education, (c) skills and knowledge, and (d) career development. For example, to implement a metrics program you must define and assign individuals to serve in the necessary roles, e.g. function point counter. Skills and knowledge on how to calculate indicators is required, courses need to be followed, and career development for function point counters should be established.

Organizing structures refer to (a) unit groupings, (b) coordinating mechanisms, and (c) authority and responsibility. The unit groupings of a metrics program include forming a metrics staff. Coordination mechanisms for collecting and presenting data should be defined. The authority and responsibility of the metrics staff should be defined, e.g. is the manager or the metrics staff responsible for prompting project managers for due data.

The main issues of concern for management practices are (a) planning and control, (b) culture, and (c) incentive schemes. For example, how are data from the metrics program used for estimating new projects? Are project indicators discussed in public or are they private to managers? Are data used to reward or sanction project managers?

We suggest to use Kirsch's model as an additional dimension in Applegate's model to assess the underlying rationale for a given software metrics program.

\section{RESEARCH APPROACH}

Our research addresses the following question: How can changes in metrics practices be assessed and made sustainable? In Section 3.1 we describe and argue for the adopted action research approach based on the IDEAL model (McFeeley, 1996). The resulting process and its organization are presented in Section 3.2. Section 3.3 describes the approach to data collection.

\subsection{Action research}

Galliers (1992) defines action research as applied research where there is an attempt to obtain results of practical value to groups with whom the researcher is allied, while at the same time adding to theoretical knowledge. 
The major advantage of action research is the close integration of research and practice. The main critique is that it may be regarded as little more than consultancy (McKay \& Marshall, 2001). McKay and Marshall argue that part of the issue concerns the way in which we currently conceptualize action research and they suggest to explicitly include a problem solving interest cycle and a research interest cycle (p. 57).

\subsection{Research organization}

Our research addresses improvement of a software metrics program and we have therefore based it on the IDEAL model of software process improvement (McFeeley, 1996). This model presents a pragmatic, operational way to improve software practices and it can be seen as a specialized version of Susman and Evered's (1978) classical action research cycle: diagnosing, action planning, action taking, evaluating, and specifying learning. The IDEAL model consists of very similar phases as shown in Figure 2. The purpose of the first phase is to initiate (I) the change process. The purpose of the second phase is to diagnose (D) the organization's current practices. In the third phase the purpose is to establish (E) the change process. The purpose of the fourth phase, acting (A), is to perform the actual changes. The purpose of the last phase, leveraging (L), is to reflect on the successes and failures of the intervention. The knowledge gained from this may be used in the next cycles of the IDEAL model and as a basis for research.

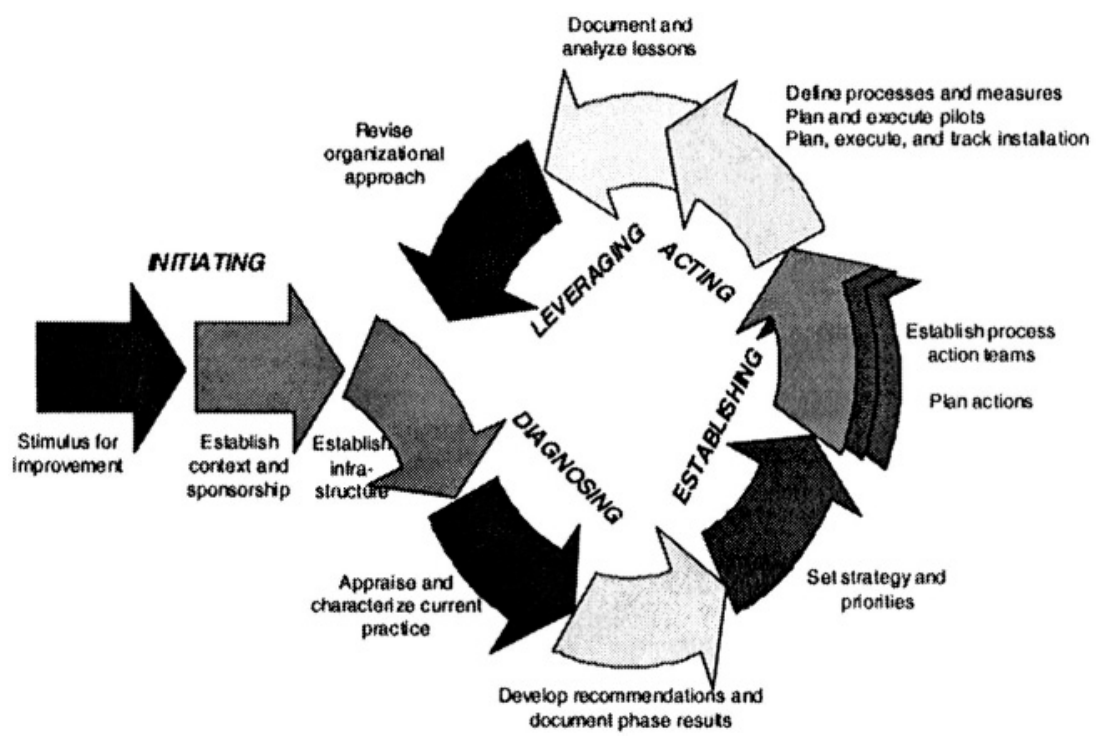

Figure 2. The IDEAL model (McFeeley, 1996) 


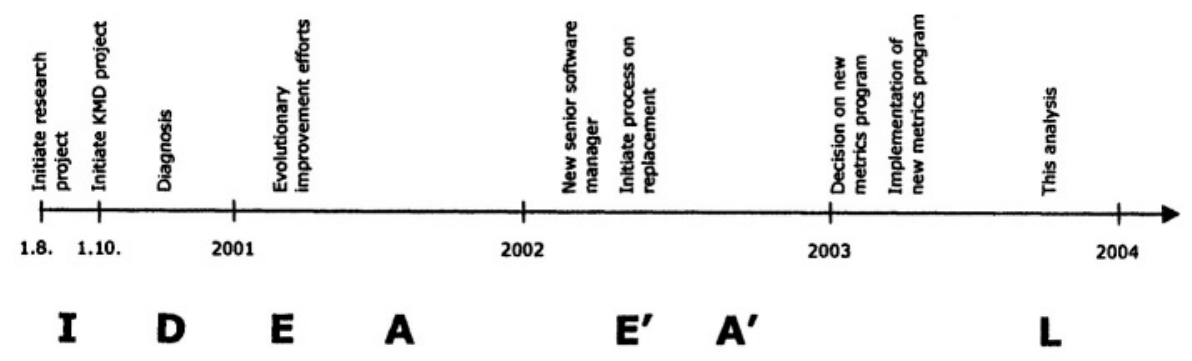

Figure 3. Timeline

Our research collaboration involved all aspects of the IDEAL model, see Figure 3. Key events are presented above the timeline and the corresponding phases of the IDEAL model are represented below the timeline. The research collaboration was initiated August $1^{\text {st }}$ 2000. The practical part, the KMDimprovement-project, was initiated October $1^{\text {st }} 2000$ (labeled I). A major activity was the diagnosis of the current metrics practices at KMD (labeled D). From the diagnosis a set of evolutionary improvements efforts were established in early 2001 (labeled E). After establishing these efforts the actual improvements were enacted (labeled A). During this phase a new responsible software director was appointed which led to a new and more radical improvement effort (labeled E' and A'). The last phase of the collaborative process was to learn from the improvement effort (labeled L). The paper presents key insights from this assessment of the impact of the improvement effort using the frameworks of Applegate (1994) and Kirsch (1997).

To manage and control the research effort it was helpful to think of it as two interrelated subprojects: 1) the KMD-improvement-project, and 2) the academic-research-project as suggested by McKay and Marshall (2001, p. 57). The KMD-improvement-project was organized as a conventional project with a project staff, a project manager and a steering committee. The researchers were participating actively in the steering committee. The academic-research-project interacted closely with the steering committee and it was driven in close collaboration between the manager of the improvement project and a university researcher (the two authors).

\subsection{Data collection}

The initial diagnosis ( $\mathrm{D}$ in Figure 3) helped understand the old metrics practices at KMD. The adopted diagnostic approach (Checkland, 1981; Andersen, 1990; Checkland \& Scholes, 1990; Pedersen, 1996) and our experience with it are reported in (Frederiksen \& Mathiassen, 2003). 
Another research team used the same data in parallel to analyze the old metrics practices based on structuration theory (Frederiksen \& Rose, 2003). This analysis was used to challenge and complement the findings of the first diagnosis to counteract the natural bias that is caused by performing action research in your own organization (Coghlan \& Brannick, 2001).

Data have been collected through semi-structured interviews with project managers, senior managers, metrics staff, and quality assurance staff. Each interview lasted for 3 hours and was documented as minutes of meetings that were subsequently corrected and approved by the interviewee. We also collected plans, decision reports, and e-mail correspondence related to metrics, minutes of meetings from the metrics staff, and documents from the organization's process improvement initiative, consultant's reports and the company intranet. Finally, one of the authors has worked as a metrics specialist at KMD for 8 years and was also manager for the improvement initiative. Throughout this process she has kept a personal $\log$ with experiences from the use of the old metrics program and design and implementation of the new program. A complete record of all emails sent to her in connection with the project was available for study. This deep engagement with the research situation meant a daily familiarity with the company.

\section{IMPROVING METRICS AT KMD}

The more than 2400 employees at KMD, including almost 700 software developers, are organized in a conventional hierarchical structure and they work at different sites. Each application team is responsible for correcting faults, supporting their users and for upgrading the applications with additional functionality and up-to-date technology. Software development is organized in projects, with project members drawn from different departments.

\subsection{The old metrics program}

KMD has a longstanding tradition of collecting simple measures, e.g. the number of faults in an application and other operational parameters as customer satisfaction, which provide visibility into problem areas. In 1996 the CEO decided to implement an elaborate metrics program to increase productivity and quality in software development. In order to identify weaknesses, KMD should be benchmarked against other software development companies. Hence, an external contractor, Compass, supplied a model (Figure 4) and a software tool to collect data suited for benchmarking. 
The basic elements of the model are projects (A1-A7) and applications (B1B5). Furthermore, data on general overhead activities (C, D and E), personnel, development software, hardware, and systems software are included.

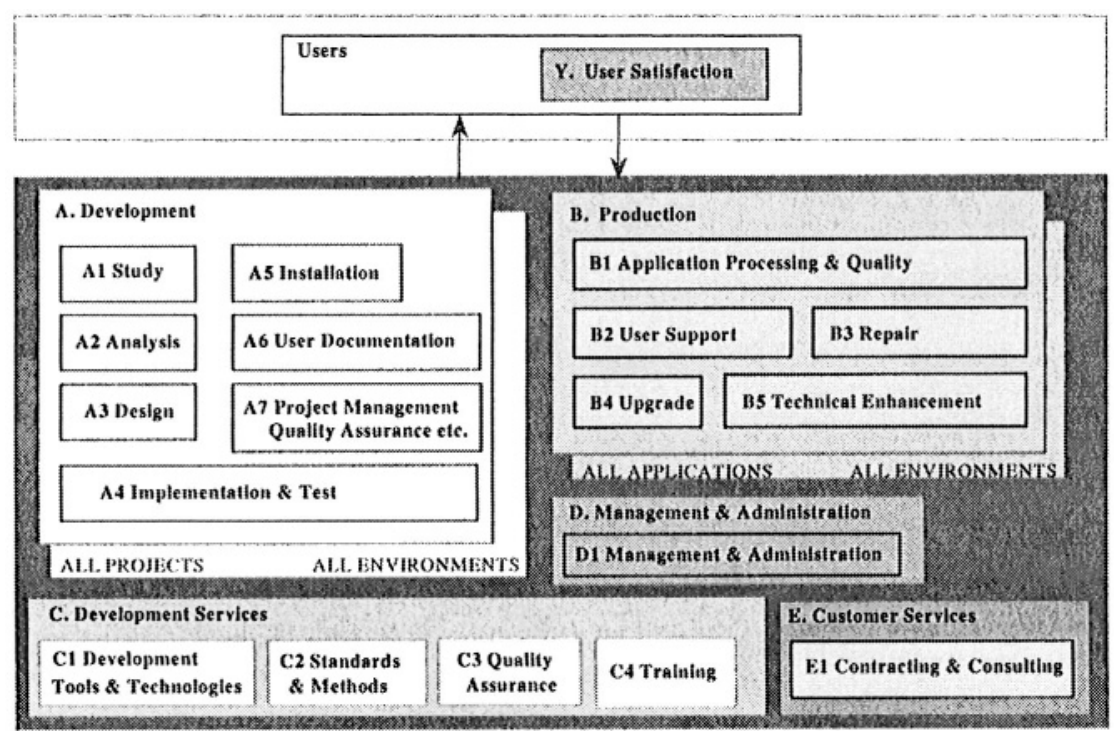

Figure 4. Basic model of old metrics program

The supply of data (measures) to the metrics program is illustrated in Figure 5. The project and team managers supplied measures on their projects and applications to the metrics program every three months. Units external to the software unit supplied measures on personnel, and expenses for consultants and software. Some data were subtracted from the ERP-system (SAP) and fed into the Compass software. Data were processed, validated and packaged at KMD before they were sent to the contractor. Compass sent results and graphs to KMD each quarter. The results were used for benchmarking KMD against a reference group at Compass. Furthermore, the results were used for internal benchmarking among the software units. Compass analyzed annually all available data and delivered a report with recommendations for managerial actions. Compass and the software process improvement organization presented the report to top management. The results informed the management's decisions on general improvement efforts to the software process. Afterwards the results were available to project and team managers, however, the results did only to a very limited extent inform their decisions. 


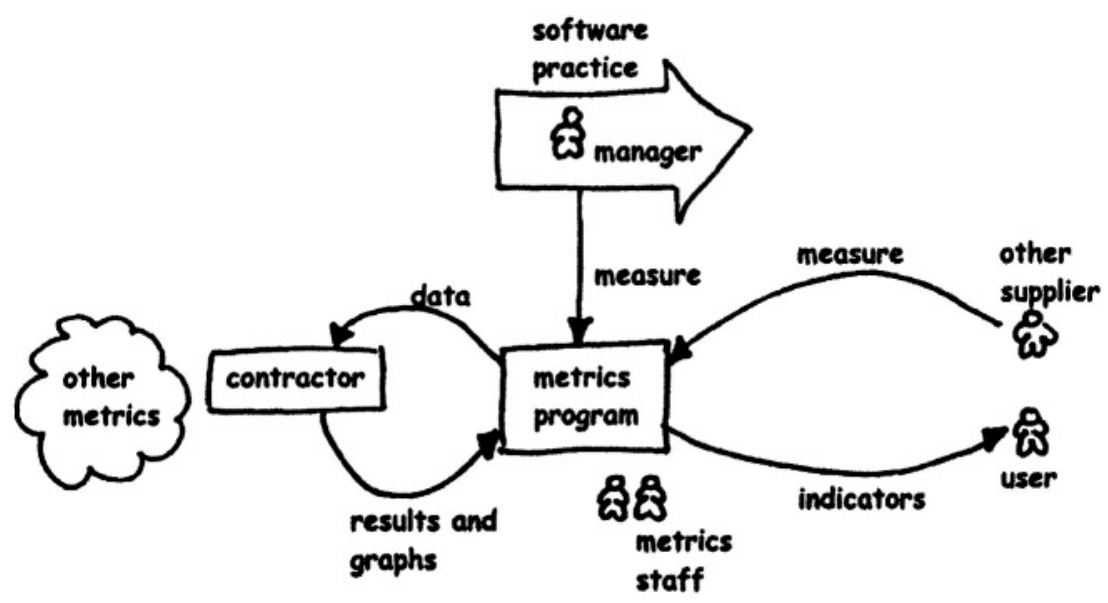

Figure 5. The old measurement process at KMD

Despite five years of intensive work with the metrics program it was difficult to point to areas at KMD where the program had made a significant impact. The metrics program was questioned by different stakeholders and the general situation at KMD made it clear that the current metrics program was far too expensive.

\subsection{The improvement process}

That situation led to the establishment of the KMD-improvement-project and the related action research as described in Section 3 (I in Figure 3).

\subsubsection{Results from diagnosis}

The initial activity was to diagnose the current metrics practices ( $D$ in Figure 3) involving all relevant stakeholders at KMD (Frederiksen \& Mathiassen, 2002; Frederiksen \& Rose, 2003). In summary, the diagnosis revealed:

- The data suppliers did not understand the definitions of metrics and measures.

- The metrics program contained a lot of data that are potentially useful for several purposes.

- The primary users were software improvement agents identifying highlevel improvements.

- Most software engineers and managers did not use the metrics program. Very few managers saw a need for it. 
- A proper interpretation of data required insights into the metrics program, the submitted measures, and the actual software practices. Few people were capable of that.

- There were few managerial responses based on information from the metrics program.

- The project indicators focused on resources and deadlines and ignored the quality of the delivered software.

\subsubsection{From evolutionary to radical improvements}

The diagnosis led to four suggested evolutionary adjustments of metrics practices. The steering committee acknowledged the diagnosis and chose to initiate two of the efforts ( $\mathrm{E}$ and $\mathrm{A}$ in Figure 3). The responsible software director was, however, replaced March 1st 2002. The latest report from Compass was soon after presented to the group of senior managers. The presentation led to a discussion of the relevance and cost of the Compassmeasurements. As a result an effort to replace the old metrics program with a new program was initiated by the newly appointed software director ( $E^{\prime}$ and $A^{\prime}$ in Figure 3).

The program was designed during the summer and fall of 2002. The annual cost of the new program was estimated to less than half of the cost of the old program. The software director and several other software managers were heavily involved. One of the authors was project manager and facilitated and documented the process and its results. In January 2003 the CEO accepted the new metrics program, the implementation was initiated, and the new metrics group was staffed.

\subsection{The new metrics program}

The new model includes four key areas as illustrated in Figure 6. Each area includes 1-3 simple indicators. The core of the metrics program is the area Development. This area includes project indicators for single projects such as the precision in the project estimates for delivery date, resources, and functionality. An indicator of project productivity is calculated from these data and published for the total set of projects at KMD. The area Maintenance includes indicators on quality and user satisfaction on applications and an indicator on the effort spent in the software unit on maintenance compared to the income for providing these services, i.e. the size of applications is measured in income and not in function points. The remaining areas, Overhead and Method \& Tools, each include a single indicator on the effort spent on management, administration and technology support compared to the effort on software development. 


\section{Overhead}

\section{Development \\ Maintenance}

\section{Method \& tools}

Figure 6. Basic model of new metrics program

The indicator on productivity is benchmarked against a reference group at The International Software Benchmarking Standards Group (ISBSG), a not for profit organization supported by industry sponsors and software metrics associations of many countries. The ISBSG offers a free, flexible project benchmarking service, which provides a facility to benchmark against a repository of software projects.

The new metrics staff consists of a manager (one of the authors) and three metrics consultants. The metrics staff is all full time personnel and each consultant covers a geographical location of KMD. Sharing experiences and knowledge are considered crucial and the staff builds its own simple tools and templates in Word and Excel. The main task of the consultants is to facilitate measures of local software projects. The manager decides which projects to measures based on the consultant's suggestion. Consultants help project managers create the basis for measuring a project and they also assist project managers estimating deadlines, resources, and functionality based on historical data. The consultant keeps track of the different versions of estimates and observes the conditions of the project in general. After a project is completed the project manager and the metrics consultant make a report, which illustrates the differences between estimates and realities. The report also illustrates changes in estimates. The project manager is responsible for sharing the report with relevant stakeholders in the unit. The consultant submits the data to ISBSG. The benchmark report is shared with the project manager and important lessons learned are shared within the software unit and with the manager in charge of software process improvement.

\section{ASSESSING IMPROVEMENTS AT KMD}

The assessment of the new metrics program was initiated in June 2003 (L in Figure 3) based on Applegate's model (1994) of key organizational 
dimensions (section 5.1 to 5.4) in combination with Kirsch's model (1997) of the underlying control rationale (section 5.5). This comprehensive approach allowed us to assess the implied changes and possible improvements to sustain the new program by systematically comparing and contrasting old and new metrics practices.

\subsection{Technical systems}

Core business processes: The core of the old program was to benchmark KMD to suggest improvements to the software operation. The benchmark included comparisons on projects (e.g. productivity and time-to-market), on applications (e.g. productivity and quality in maintenance), and general indicators (e.g. time for management and administration and cost for software tools). The new program includes benchmark of KMD on only one indicator (project productivity). This benchmark satisfies top management needs based on data from ISBSG. Indicators are now used to set the goals of the software units. There are two major changes in the process. First, the purpose of the metrics program has shifted from identification of improvements towards management support. Second, the focus has shifted from external benchmarking towards learning from specific projects about details on the software operation, e.g. staffing of projects.

Product/process technology: The core technology of the old program was the model in Figure 4 and the related tools and templates supplied by Compass. The metrics staff developed local tools and checklists to support the measurement tasks. Data were extracted from the BRP system, modified and filled into the Compass tools. The new model (Figure 6) has no details on applications and general activities but more details on projects including major changes. These metrics are defined in close cooperation with software managers. The indicators are inspired by the Compass model, but the metrics staff is expected to define other relevant metrics, and the set of data is expected to change and grow over time. The replacement of the model meant that tools, templates, and checklists were replaced, too. Excel is used to record details of function point counts. Data are extracted from the ERP system and primarily used without modification. When needed data are adjusted in the ERP system. There are three major changes in technology. First, the model has shifted from generic Compass metrics towards specific KMD metrics. Second, the measurement process is now simpler, cheaper and more flexible. Third, the process is more tightly linked to the ERP system.

Tasks: The tasks of the metrics staff in the old program were interpretation and adaptation of Compass' model and data collection. The metrics staff was responsible for coordinating data collection, assisting in 70 
validation of data and presenting the results. The metrics staff was also available for more detailed presentations and debates of the indicators. The model and routines of the new program are developed and maintained by the metrics staff. The decision on which projects to measure is taken by software management guided by metrics staff and potential relevance for estimation of future projects. The border of the responsibilities between the metrics staff and the data suppliers has changed. Now the metrics staff collects data and prompts project managers and other relevant people for validation. Furthermore, the metrics consultant presents project indicators to the project manager. The metrics staff is still available for more detailed presentations and debates of indicators. The major change is that the metrics staff is more involved in projects and process execution has shifted from being outsourced assisted by internal experts towards being in-house facilitated by internal experts and with considerable degree of management participation.

\subsection{People}

Roles: A set of roles was explicitly defined in the old program. A Compass-controller coordinated data collection in each software unit and supported the project and application managers in data collection. Furthermore, the Compass-controller supplied data on general activities like time spent on management and administration and the number of employees in the software unit. The software unit also had a local function point counter. The collaboration of the local Compass-controller and function point counter was crucial to obtain valid data. A specialist from the methods department was responsible for the metrics program, and another specialist was responsible for the function point method and for using data for estimation. In the new metrics staff there are only two roles - the metrics consultant and the team leader. The metrics staff subtracts data from the ERP system and asks the local controllers to validate them. The formal roles of the project and software managers haven't changed. The objective of improving the program was to adjust actual behaviors to fit managerial needs. The new metrics program is still used to support software process improvement. However, this role is now distributed with more emphasis on learning within and from projects. The major change is that there are fewer roles and hence fewer interfaces between roles.

Education: Metrics specialists were educated by consultants from Compass in the old program. The software and projects managers were introduced to the Compass-measurements. Later they were given a detailed introduction as preparation for measuring their projects and applications. Each time indicators were presented some kind of introduction was given. The new program was introduced through several sessions with senior 
managers. Education of the metrics staff was based on available literature and there was more focus on organizational aspects. The metrics consultants now count function points, but no training was needed because they used to be function point counters. The specific details of indicators were introduced through one-on-one presentations of results from the unit in question. These presentations were followed by a joint discussion between senior managers. Project managers are introduced to the new metrics program when their project is to be measured. The major change is that managers on all levels learn more by being part of the process. This is possible since there are fewer people involved and the metrics program is simpler.

Skills \& Knowledge: A specialist from the methods department with skills and knowledge on measurements managed the old and now the new program. In the old program the Compass-controllers were appointed based on their insight into administrative routines. They were less skilled on software processes and project management. The Compass-controllers were supposed to help managers with interpretation but it rarely happened. The new metrics consultants are all very skilled on software processes. They are experienced software developers and project managers who have worked at KMD for several years. The major change is the move from Compass related skills to KMD specific skills. Managers are required to understand and share KMD's perception of software processes, and the metrics staff actively facilitates their interpretation of indicators.

Career Development: Working with the metrics program is not part of a formal career at KMD. The work has, however, changed to become more prestigious. The metrics consultants now have a central and acknowledged position in the local management groups. The software director used to prompt the manger of the metrics program for occasional presentation of indicators in the group of senior managers. The present software director treats the metrics manager as a personal assistant on these matters. Overall the position of the metrics staff has become more visible and central.

\subsection{Organizing structures}

Unit Groupings: The organizing structures of the software units have not been affected. An important player then and now is the forum where the senior managers meet with each other and the manager of the methods department. The old metrics staff was organized in two groups chaired by methods specialists. The function point group included all function point counters, and the Compass-group included all Compass-controllers, the Compass-coordinator and the specialist on Compass. All members worked part time on the metrics and had different managers. The new metrics consultants are organized in one coherent team with one manager, and they 
work full time on the metrics program. The major change is that the metrics staff now works full time and is organized as a smaller and more coherent team.

Coordinating Mechanisms: The primary coordinating mechanism of the two groups was mutual orientation between the chairmen and coordination between the Compass-controller and function point counter of each unit. The dissemination of results followed the conventional hierarchy of the software units. Some indicators were in addition presented in a monthly report composed by the financial department. Project indicators were presented to the project manager. However, it was not expected that the project manager passed the indicators on. The new metrics staff meets on a regular basis to coordinate and discuss the program. The staff now publishes a set of overall indicators, e.g. the company productivity. The metrics consultant presents indicators from a single project to the project manager, who then is responsible for reporting them through the management system along with other information on the project. The project manager qualifies the indicators and presents them to the next management level. The aggregated indicators are presented in a management information report along with other information. The major change is that project managers own their project indicators, and that the aggregated indicators are reported as an integral part of management information in the software units.

Authority \& Responsibility: The old program was introduced by the present CEO and sponsored by the methods department. However, the managerial responses were sparse. The old metrics program was perceived as yet another administrative burden on project managers. The new metrics program is introduced and sponsored by the software director. The director is excited about the program, and he contributed significantly to its design and adoption. The metrics consultants are perceived as representatives of the program and the software director. Hence they have more authority. The major change is that the responsible software director has given the metrics staff authority to measure software processes and act as experts and facilitators on measurements.

\subsection{Management practices}

Planning \& Controls: In the old program Compass' definition of a project was used to benchmark projects. The data collected included various characteristics of a project and effort spent in the different phases. Project managers at KMD are solely responsible for planning and controlling their projects. The project indicators were, however, calculated post mortem by Compass and they ignored changes in projects. The purpose was measuring overall performance more than giving the project manager data for control. 
The new metrics consultants assist the project managers in estimation and ensuring that their plans are suitable for calculating indicators. Project data are supplemented with the metric consultant's observations on software quality. The new project indicators are still used for monitoring overall performance, but the main purpose is to support and learn from projects. The metrics consultants are involved in the projects and they calculate the indicators at several occasions to assist the project manager in high-level tracking and control. The ISBSG benchmarking is flexible which means that the program can include or cope with new aspects of software projects. The major change in metrics practices is that the staff is more involved in projects and the metrics program is more flexible in the way projects are measured.

Culture: Despite skepticism towards comparisons with other companies senior managers have increasingly appreciated the usefulness of indicators and demanded that software performance should be benchmarked. Despite unfortunate cases of public blaming of project managers based on indicators, the project managers remained very open about their Compass indicators. The project managers have now taken ownership of their data and teamed up with the metrics consultants to provide valid data and to subsequently use data to improve management practices, e.g. related to estimation, staffing, and monitoring. The major change is that the perceived role of the metrics consultant has changed from supervisor and controller to colleague and team player.

Incentive Schemes: The software managers were not motivated to actively participate in, contribute to, or use the old metrics program. No incentive schemes were set up to facilitate their involvement. The overall incentive schemes at KMD have traditionally given highest priority to meeting deadlines. The new program includes indicators that focus on effort and functionality. However, meeting deadlines is still the primary objective. The strong interest of the software director motivates other managers to become involved in the new metrics program. The indicators are used actively to set goals for the units, and eventually the indicators contribute to the calculation of each manager's bonus. The major change is that the indicators are used in setting and tracking the goals of the software units and software managers on all levels take an interest in the metrics program.

\subsection{Metrics rationale}

Looking at the metrics rationale underlying these emerging practices we can identify changes in mode of control (Kirsch, 1997).

Outcome: The indicators in the old program were calculated after completing the project. This suggests outcome control. However, no goals 
were set for outcome, and the indicators from the program generated no managerial response. The response was limited to questioning data quality and discussing possible managerial actions. In the new program goals are set for indicators. The indicators are as a minimum calculated after completing the project, but in many cases they are also calculated during the project. Changes in a project lead to new or modified goals. The software director requires explanations and actions from the software managers when indicators deviate from goals.

Behavior: The old project measures were not an integral part of the project manager's planning and control activities. The metrics program existed in isolation, and the project manager submitted data only when required to do so. There was no behavior control. The new measures are an integral part of project management. The project manager and the consultant work closely together to estimate and plan the project. When a change occurs they adjust the goals and the consultant assist in provision and interpretation of indicators. KMD's software process includes this practice and the project managers accept it. This implies elaborate behavior control.

Clan: The old metrics staff did not share common values and beliefs and some of the Compass-controllers expressed concerns about the value of the metrics program. The software process improvement group was initially optimistic about the program, but they resigned, as they experienced how measures were not used. Very few project managers expressed that they valued measurements. All members of the new metrics staff believe in the value of the program and its intended use. The project managers see the value of measurements to help identify and address the problems they face. However, there are still project managers who have no experience with the metrics program, and therefore don't have enough insight to acknowledge the potential of the metrics program.

Self: This mode of control was not intended or perceived as essential in either the old metrics program beyond what is implied by the other modes of control. In the new program there is an explicit focus on each program and unit manager and the performance of the dedicated metrics consultants. Project managers own data from their project and their performance assessment includes data from the metrics program.

KMD has, in summary, moved from non-specific outcome control towards focused outcome control complemented with behavior control and elements of clan and self control. The key controllers have shifted from the metrics staff (controlling improvement efforts) to software managers (controlling the software process). 


\section{DISCUSSION}

The above systematic assessment of metrics practices and the following discussion constitutes the key learning from our research ( $\mathrm{L}$ in Figure 3). Our guiding research question is: How can changes in metrics practices be assessed and made sustainable? We address this question by examining the following more specific issues: Does the new metrics program solve the identified problems? Does the new metrics program represent a sustainable improvement? What are the lessons from the systematic assessment?

Does the new metrics program solve the identified problems? The identified problems with the old metrics problem (Section 4.2.1) were the reason for and the basis for designing the new program. The problems have been addressed as follows. First, the data suppliers did not understand the definitions of metrics and measures. Now, the metrics staff collects the data and supports project managers in measuring their projects. This high level of interaction facilitates a shared understanding of the intended meaning of indicators. Second, the primary use of the metrics was by software improvement agents for high-level software process improvement. Most software engineers and managers did not use the metrics program, and few managers saw a need for it. The metrics program has been redesigned to contain indicators, which are in demand by managers, and the use of indicators for estimating projects has been emphasized. At the same time the metrics program includes data wanted by the metrics staff for low-level software process improvement. Third, a proper interpretation of data required insights into the program, the submitted measures, and the actual software practices. Few people were capable of that, hence, results were often presented in quite general terms and the readers were left to interpret them on their own. Now, the metrics program is simpler with specific metrics tailored for KMD, and the metrics staff facilitates interpretation of indicators. Fourth, the old project indicators focused on resources and deadlines and ignored the quality of the delivered software. The new project measures include data on software quality. Lastly, there were few managerial responses based on information from the program. Now, indicators are used for setting goals for managers.

Does the new metrics program represent a sustainable improvement? The new program constitutes an improvement because it addresses as argued above the identified problems with software metrics at KMD. The program is therefore perceived as being better. At the same time it is considerably cheaper, 3 million kroner per year compared to 7 million kroner per year (section 4.2.2). The new program has also adopted several of the recommendations in the literature. The program now primarily supports managers by supplying indicators of projects and applications (Grady, 
1992). At the same time it still supports identification of project specific improvements (Hall \& Fenton, 1997). The program generally emphasizes use of indicators over collection of comprehensive sets of data (Niessink \& Vliet, 1999). Indicators are used in setting and tracking the goals of software units and software managers on all levels have initially taken an interest in the metrics program. Moreover, data collection is more automated through extensive integration with the ERP system (Hall \& Fenton, 1997). The metrics staff now works full time and is organized as a smaller and more coherent team corresponding to Hall \& Fenton's (1997) recommendation of a dedicated metrics staff. There has been a considerable degree of management participation in the design and implementation of new metrics program. As a result managers on all levels have learned about metrics, more managers are committed to the metrics program and act as champions, and the metrics program is better suited to managerial needs (Hall \& Fenton, 1997). Metrics "can only be useful to those controllers who truly understand the meaning and implications of the data" (Kirsch, 1996, p. 4) and having the metrics staff work closely with managers supports this.

The systematic comparison between the old and the new metrics program revealed a number of key changes as presented in Section 5. However, it also revealed a number of issues that needs to be addressed to further improve and sustain the metrics program. The analysis showed that all the organizational aspects presented by Applegate (1994) had been addressed, but some needs more attention. First, and most importantly, the incentive schemes for the project managers are implicit and long range. Project managers are motivated by the demand of indicators from their managers, and the anticipation of the usefulness of project indicators for estimating future projects. The first measurements have shown that the motivation increases when a project manager experiences how indicators can be used, e.g. to support staffing. Their motivation could, however, be stronger if there were more explicit and short range incentive schemes. It is also at this point unclear how the new program affects the relation between project and software managers. Discussions are needed to clarify what the roles are, and how project and software managers can inspire each other to generate effective responses based on indicators from the program. It still remains to be seen what the sustainable level and quality of managerial responses will be in the new set-up. The tasks, roles, and technology for distilling and spreading best practices based on project measurements are also not well defined. Project managers are expected to learn from their own projects, and the metrics consultants should distill general patterns across projects. To achieve any effects it is critical that the project managers and metrics consultants are observant, analytical and proactive. The insights and impacts from this learning process are of interest to senior managers and the 
responsible for software process improvement. However, it is not well defined how results are identified, presented and diffused.

What are the lessons from the systematic assessment? The comprehensive organizational analysis can in this way help develop a more sustainable program. The design and implementation of the new program was guided by the identified problems (see Section 4.2.1) and recommendations in the literature. Yet the analysis based on Applegate's framework (1994) offered a comprehensive organizational understanding of the program and its operation and it revealed important areas, which need further attention. Adding Kirsch's concepts of control mechanisms (1997) helped us understand and design the underlying control rationale of the metrics program. This analysis stressed in a very direct way the importance of making active use of indicators (Niessink \& Vliet, 1999, Iversen \& Kautz, 2001) and it enriched our understanding of different approaches to control software practices. The adopted approach to systematic assessment is easy and inexpensive to use and the process can be completed within a very limited time frame. Our experience shows that the effort is worthwhile. Finally, it is important to note, that the approach focuses on first-order improvements, i.e. on assessing improvements of the metrics program itself. Eventually, a useful metrics program must demonstrate second-order improvements as well, i.e. improvements in software process performance, to legitimize the cost of running the program and to ultimately assess the ROI of the metrics improvement effort.

\section{CONCLUSION}

Many software organizations fail to get satisfactory benefit from their investments in metrics programs (Dekkers, 1999). Software managers are therefore advised to give priority to critical assessments and subsequent improvement of software metrics programs (Mendonça \& Basili, 2000). The presented approach for assessing a metrics program stresses the organizational completeness of the metrics program (Applegate, 1994) and the underlying control rationale (Kirsch, 1997). Software managers are encouraged to adopt this inexpensive and comprehensive scheme to critically assess improvements in metrics programs. Our experiences suggest that the research community should give priority to research that emphasizes metrics programs as organizational systems rather than isolated technological tools for measuring software processes. Future research could further explore these opportunities by adopting well-established approaches to assess metrics programs as management information systems (see for example DeLone \& McLean, 2003). Additional research is also required to 
assess and further develop the presented approach to assess improvements in metrics practices for practical use.

\section{REFERENCES}

Andersen, P.B. (1990) A Theory of Computer Semiotics. Semiotic Approaches to Construction and Assessment of Computer Systems. Cambridge University Press, Cambridge.

Applegate, L.M. (1994) Managing in an Information Age: Transforming the Organization for the 1990s In R. Baskerville, S. Smithson, O. Ngwenyama, and J.I. DeGross, Eds., Transforming Organizations With Information Technology, (A-49), 15-94. Amsterdam: Elsevier.

Avison, D., F. Lau, M.D. Myers and P.A. Nielsen (1999) Action research, Communications of the ACM, Vol. 42, No. 1, January, pp. 94-97.

Berry, M. and R. Jeffery (2000) An instrument for assessing software measurement programs, presented at Empirical Software Engineering Conference, Staffordshire, UK.

Checkland, P. (1981) Systems Thinking, Systems Practice. John Wiley.

Checkland, P. and J. Scholes (1990) Soft Systems Methodology in Action. John Wiley.

Chidamber, S.R. and C.F. Kemerer (1994) A metrics suite for object oriented design, IEEE Transactions on Software Engineering, Volume 20, no. 6, page 476-493.

Coghlan, D. and T. Brannick (2001) Doing Action Research in Your Own Organization, Sage, London.

Dekkers, C.A. (1999) The secrets of highly successful measurement programs, Cutter IT Journal 12(4), 29-35.

deLone, W.H. and McLean, E.R (2003) The deLone and McLean model of information systems success: A ten-year update, Journal of Management Information Systems 19(4), pp. 9-30.

Fenton, N.E. and M. Neil (1999) Software metrics: Successes, failures and new directions, The Journal of Systems and Software (47:2-3), pp. 149-157.

Frederiksen, H.D. and L. Mathiassen (2002) Diagnosing Metrics Practices in a Software Organization. In New Perspectives on Information Systems Development: Theory, Methods and Practice. Kluwer Academic, New York, USA.

Frederiksen, H.D. and L. Mathiassen (2003) Diagnosing metrics practices in a software organization. Submitted for IEEE Transactions on Engineering Management.

Frederiksen, H.D. and J. Rose (2003) The social construction of the software operation, Scandinavian Journal of Information Systems, Vol. 15.

Galliers, R.D. (1992) Choosing Information Systems Research Approaches. In: R. Galliers, editor. Information Systems Research: Issues, Methods and Practical Guidelines. Blackwell Scientific Publications, Oxford.

Grady, R.B. (1992) Practical Software Metrics for Project Management and Process Improvement, Prentice Hall.

Hall, T. and N. Fenton (1997) Implementing effective software metrics programs, IEEE Software 14(2), 55-64.

ISBSG www.isbsg.org.au

Iversen, J. and K. Kautz (2001) Principles of metrics implementation, in Improving Software Organizations: From Principles to Practice, L. Mathiassen, J. Pries-Heje, and O. Ngwenyama, Eds., pp 287-305, Addison-Wesley, Upper Saddle River, New Jersey. 
Iversen, J. and L. Mathiassen (2003) Cultivation and engineering of a software metrics program, Information Systems Journal, (13:1), January, pp. 3-20.

Jones, C. (1996) Applied Software Measurement, McGraw-Hill.

Kirsch, L.J. (1996) The Management of Complex Tasks in Organizations: Controlling the systems development process, Organization Science, Vol. 7, Issue 1, January-February, pp. 1-21.

Kirsch, L.J. (1997) Portfolios of control modes and IS project management, Information Systems Research, Vol. 8, No. 3, September, pp. 215-239.

Kitchenham, B., S.L. Pfleeger, and N. Fenton (1995) Towards a framework for software measurement validation, IEEE Transactions on Software Engineering 21 (12), 929-944.

Kock, N. \& F. Lau (2001) Introduction. Information systems action research: serving two demanding masters, Information Technology \& People, Vol. 14 no. 1 (2001), pp. 6-11.

Mathiassen, L. (2002) Collaborative practice research, Information Technology \& People (14:4), pp. 321-345.

McFeeley, B. (1996) IDEAL A User's Guide for Software Process Improvement, CMU/SEI96-HB-001.

McKay, J \& P. Marshall (2001) The dual imperatives of action research, Information Technology \& People, Vol. 14, no. 1, pp. 46-59.

Mendonça, M.G. and C.R. Basili (2000) Validation of an approach for improving existing measurement frameworks, IEEE Transactions on Software Engineering 26 (6), 484-499.

Niessink, F. \& Vliet H. van (1999) Measurement should generate value, rather than data, in Proceedings of the Sixth International Software Metrics Symposium, pp 31-38, Florida, USA.

Pedersen, M.K. (1996) A Theory of Informations. Samfundslitteratur, Copenhagen.

Susman, G. and R. Evered (1978) An assessment of the scientific merits of action research, Administrative Science Quarterly, Vol. 23, pp. 582-603.

Wasserman, A.I. (1996) Towards a discipline of software engineering, IEEE Software, Vol. 13, no. 6. November, pp. 23-31. 